\title{
EDUKASI GERAKAN BERSIH PANTAI DAN LAUT DI PULAU TUNDA
}

\author{
Ferry Dwi Cahyadi*, Kukuh Widiyanto, Kukuh Prakoso \\ Pendidikan Kelautan dan Perikanan, Kampus UPI Serang, Universitas Pendidikan Indonesia \\ Jl. Ciracas No.38, Serang, Kota Serang 42116, Banten \\ "Email: ferrydc@upi.edu
}

\begin{abstract}
Abstrak
Sampah di laut terutama sampah plastik saat ini menjadi permasalahan setiap negara terutama yang memiliki wilayah pesisir dan pulau-pulau kecil seperti Indonesia. Permasalahan tersebut menjadi lebih rumit ketika sampah berada di pulau-pulau kecil yang berpenghuni karena minimnya sumberdaya dan daya dukung lingkungan di pulau kecil. Pulau kecil seperti Pulau Tunda di Kabupaten Serang, Provinsi Banten merupakan salah satu obyek wisata dengan ekosistem pesisir yang cukup lengkap. Sebagai obyek wisata maka banyak sampah dari kegiatan wisata, rumah tangga, maupun yang terbawa arus. Sampah di Pulau Tunda sudah cukup banyak dan masih kurang tertangani. Kegiatan pengabdian ini bertujuan untuk memberikan edukasi mengenai ekosistem pesisir dan laut, bahaya sampah plastik, dan melakukan gerakan bersih pantai dan laut bersama warga serta wisatawan di Pulau Tunda. Metode yang digunakan adalah penyuluhan dan terjun aksi bersama membersihkan sampah. Hasilnya adalah titik penumpukan sampah di Pulau Tunda sudah banyak berkurang dari hasil evaluasi dan masyarakat dapat memilah sampah.
\end{abstract}

Kata kunci: gerakan bersih pantai dan laut, pulau kecil, sampah plastik

\section{PENDAHULUAN}

Indonesia merupakan negara maritim dengan wilayah pesisir dan laut yang luas. Indonesia juga merupakan negara penyumbang sampah plastik ke laut nomor 2 terbesar di dunia setelah China yakni 0,48-1,29 MMT/tahun, 1 MMT (million metric ton $)=1.000 .000 .000 \mathrm{~kg}$ (kilogram) (Jambeck dkk., 2015). Sebagai negara maritim, Indonesia wajib melakukan tindakan pengurangan dan pencegahan pembuangan sampah ke laut dan pesisir melalui berbagai kebijakan dan program. Kebijakan yang sudah dikeluarkan salah satunya adalah Peraturan Presiden No.16 tahun 2017 tentang Kebijakan Kelautan Indonesia yang menekankan menjaga lingkungan pesisir dan laut dari sampah terutama sampah plastik. Hal tersebut dikarenakan sampah plastik sangat lama terurainya sehingga mengganggu ekosistem laut (Gall dan Thompson, 2015). Sampah plastik juga dapat menyebabkan gangguan kesehatan masyarakat yang mengkonsumsi ikan laut yang mengandung mikroplastik (Thompson dll., 2009; Rochman dkk., 2015). Biota laut juga terancam sampah plastik seperti terlilit, tersedak, sampai meninggal (Gregory, 2009).

Berbagai program, kegiatan baik formal maupun informal di Indonesia untuk mengurangi sampah sudah banyak dilakukan terutama di pesisir kota besar dan obyek wisata bahari popular. Hal tersebut didasari terutama pada obyek wisata bahari populer akan menghasilkan sampah yang banyak. Meskipun begitu banyak sampah di pesisir dan laut seringkali terbawa arus dan terbawa ke pulau-pulau kecil. Indonesia sebagai negara kepulauan memiliki banyak pulau kecil yang berpenghuni. Bagi mereka yang menguni pulau kecil sampah-sampah di pesisir dan laut akan lebih terasa dampaknya karena pulau-pulau kecil memiliki keterbatasan daya dukung, sumberdaya dan kapasitas asimilasi perairannya (Farhan dan Lim, 2011; Sur dkk., 2018). Salah satu pulau kecil yang terdampak sampah adalah Pulau Tunda (Maharani dkk., 2018).

Pulau Tunda merupakan salah satu pulau kecil yang berpenghuni di Kecamatan Tirtayasa, Kabupaten Serang, Provinsi Banten. Pulau ini merupakan obyek wisata yang cukup sering dikunjungi oleh masyarakat terutama dari Banten, Jakarta, dan Lampung saat akhir pekan dan musim memancing. Kondisi pesisir di Pulau Tunda saat ini banyak dijumpai sampah-sampah di pantai seperti tas plastik, botol plastik, sandal, sepatu, popok dll. Sampah-sampah tersebut selain dari aktivitas wisata yang ada disitu juga berasal dari Lampung, Banten, dan Jakarta yang terbawa arus (Maharani dkk., 2018). Kondisi tersebut ditambah dengan kurangnya fasilitas pembuangan sampah baik di wisma atau guesthouse maupun di sekitar pantai. Selain itu sampah-sampah banyak terjebak di bakau dan vegetasi pantai lainnya tanpa ada tindakan. Hal tersebut jika dibiarkan terus 
menerus akan menyebabkan kondisi pantai yang kotor sehingga mengurangi pendapatan dari kegiatan wisata, tercemarnya ikan yang dikonsumsi, dan terancamnya biota-biota di perairan Pulau Tunda. Tujuan dari kegiatan pengabidan ini adalah memberikan edukasi mengenai ekosistem pesisir dan laut, bahaya sampah plastik, dan melakukan gerakan bersih pantai dan laut bersama warga serta wisatawan sehingga terbentuk kesadaran bersama akan pentingnya menjaga lingkungan pesisir dan laut terutama di Pulau Tunda dari sampah.

\section{METODE}

Khalayak sasaran pada kegiatan pengabdian ini adalah masyarakat dan wisatawan di Pulau Tunda yang dilaksanakan pada bulan Agustus-Oktober 2019. Lokasi Pulau Tunda ditunjukkan pada Gambar 1. Metode yang digunakan dalam kegiatan pengabdian masyarakat ini berupa pendidikan masyarakat dengan kegiatan penyuluhan dan terjun aksi bersama ke lokasi langsung. Tahap pertama dilaksanakan di lokasi sekitar obyek wisata dan permukiman penduduk berupa kegiatan penyuluhan mengenai edukasi ekosistem pesisir dan laut, dan bahaya sampah plastik. Tahap kedua aksi bersama membersihkan sampah di pesisir Pulau Tunda. Evaluasi dilakukan pada Desember 2019 untuk mengetahui apakah masih ada pencemaran sampah di lokasi perairan Pulau Tunda.
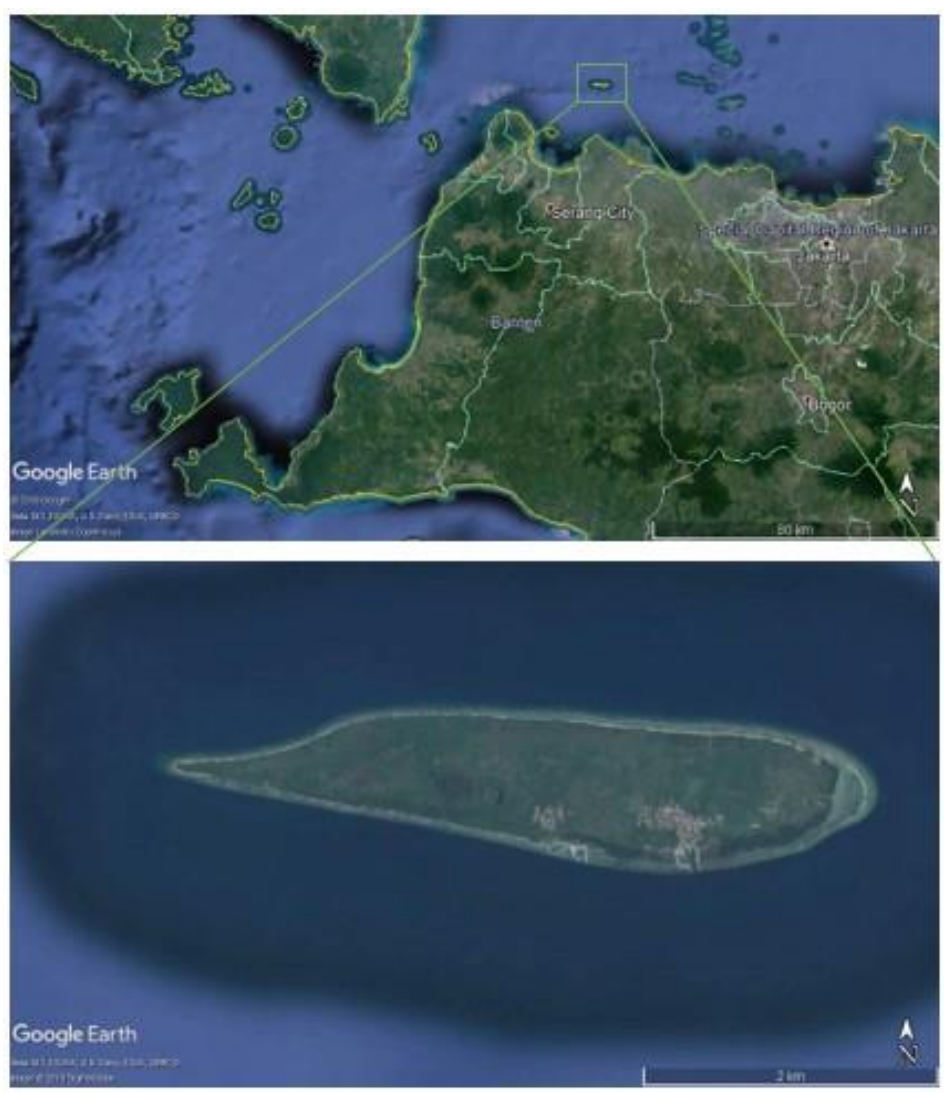

\section{Gambar 1. Lokasi Kegiatan Pengabdian di Pulau Tunda}

\section{HASIL DAN PEMBAHASAN}

Kegiatan pengabdian tahap pertama berupa kegiatan penyuluhan edukasi ekosistem pesisir dan laut serta bahaya sampah plastik. Peserta masyarakat antusias mengikuti kegiatan edukasi tersebut yang diselenggarakan di lapangan dekat guesthouse milik warga. Beberapa wisatawan tertarik untuk mengikuti kegiatan tersebut. Selain itu untuk kegiatan penyuluhan bagi wisatawan juga dilaksanakan di dekat hutan mangrove. Pada wilayah hutan mangrove banyak sampah-sampah yang terjebak di perakarannya. Lokasi tersebut dekat dengan pantai sehingga banyak wisatawan yang memperoleh edukasi mengenai pentingnya menjaga lingkungan pesisir dari sampah plastik.

Kegiatan pengabdian tahap kedua berupa aksi bersama gerakan bersih pantai dan laut di pesisir dan perairan Pulau Tunda. Warga masyarakat dan wisatawan yang terlibat wajib 
menggunakan rompi pengaman (life jacket). Kegiatan ini dilakukan di sepanjang pesisir Pulau Tunda yang terdapat sampah. Kegiatan bersih-bersih pantai dan laut ini yang mengikuti kebanyakan masih muda karena bersemangat untuk diajak berkeliling Pulau Tunda dan membersihkan sampah (Gambar 2).

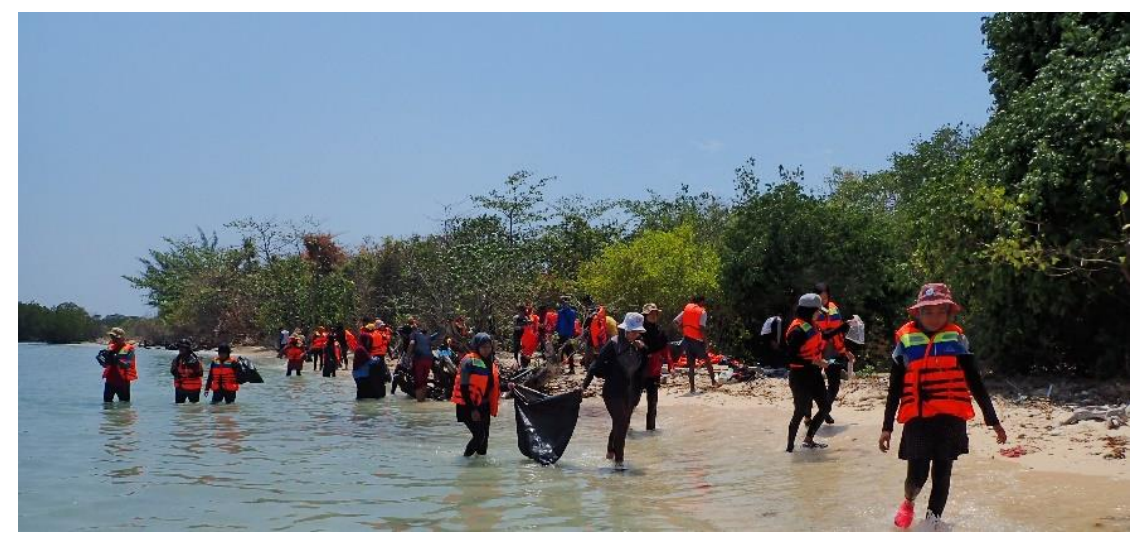

Gambar 2. Peserta Gerakan Bersih Pantai dan Laut di Pulau Tunda

Berdasarkan hasil kegiatan gerakan bersih pantai dan laut ditemukan fakta bahwa sampah yang dijumpai di pesisir Pulau Tunda kebanyakan berupa sampah plastik seperti air minum kemasan, styrofoam, dan pembungkus makanan. Maharani dkk (2018) menyebutkan juga bahwa pembungkus makanan merupakan sampah yang paling sering ditemukan di Pulau Tunda. Sampahsampah yang terkumpul kemudian dipilah dan sebagian didaur ulang oleh warga untuk dijadikan ecobrick. Sampah plastik dan kertas juga dapat digunakan sebagai media pembelajaran sekolah dasar (Fakhriyah dkk., 2016). Hal tersebut juga diperlukan agar pembelajaran di sekolah dasar lebih inovatif dan menarik bagi siswa meskipun bersekolah di pulau kecil yang terbatas listrik dan sarana prasarananya. Pulau Tunda memiliki 1 sekolah dasar dan 1 sekolah menengah pertama, untuk jenjang sekolah menangah atas atau kejuruan warga harus ke daratan utama di Kabupaten/ Kota Serang.

Evaluasi yang dilaksanakan menunujukkan bahwa peserta adanya penurunan jumlah titik penumpukan sampah saat bulan Juli 2019 yaitu sebanyak 10 titik menjadi 2 titik pada bulan Desember 2019. Penumpukan sampah tersebut perlu dimonitoring kembali pada bulan-bulan berikutnya agar keberlanjutan kebersihan lingkungan pantai dan laut di Pulau Tunda tetap terjaga (Gambar 3). Hal tersebut penting dikarenakan Pulau Tunda sebagai pulau kecil memiliki keterbatasan akses dan sumberdaya misalnya karena penumpukan sampah menyebabkan penyakit bagi warga padahal di Pulau Tunda hanya terdapat puskesmas jika memerlukan penanganan lebih lanjut harus ke daratan utama yang memakan waktu kurang lebih 2 jam. Selain itu sampah-sampah yang masih berada di pantai maupun mangrove akan dapat mengurangi minat wisatawan untuk datang kembali (Cahyadi dkk., 2018).

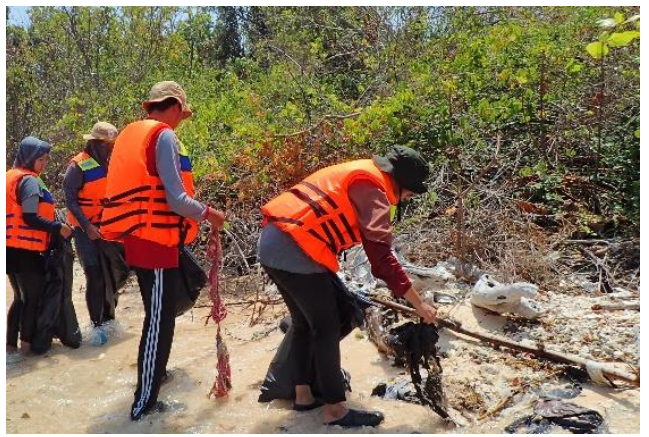

(a)

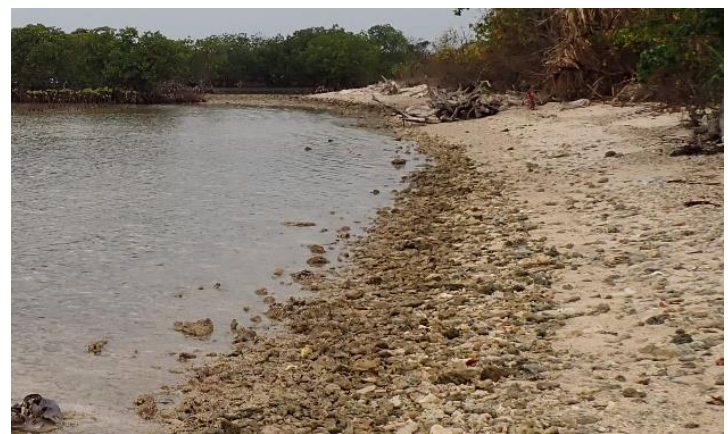

(b)

Gambar 3. (a) Sampah yang diambil di sepanjang pantai Pulau Tunda. (b) Kondisi pantai di Pulau Tunda yang sudah dibersihkan 


\section{KESIMPULAN}

Kegiatan pengabdian edukasi gerakan bersih pantai dan laut di Pulau Tunda dapat memberikan pemahaman pentingnya menjaga lingkungan pantai dan laut dari sampah. Kebersihan yang terjaga secara tidak langsung juga akan menarik wisatawan untuk datang berkunjung kembali ke Pulau Tunda.

\section{DAFTAR PUSTAKA}

Cahyadi, F.D., Khakhim, N., dan Mardiatno, D. (2018). Integrasi SWOT dan AHP dalam Pengelolaan Ekosistem Mangrove di Kawasan Wisata Bahari Gugusan Pulau Pari. Jurnal Pariwisata Pesona. 3(2). DOI: 10.26905/jpp.v3i2.2336

Fakhriyah, F., Wanabuliandari, S., dan Ardianti, S. D. (2016). Pendampingan Pemanfaatan Sampah Plastik dan Kertas untuk Media Pembelajaran Inovatif bagi Guru di SDN 5 Bae, Kudus. Jurnal Pengabdian Pada Masyarakat. 1(1), 48-55. DOI: 10.30653/002.201611.8

Farhan, A.R., and Lim, S. (2011). Resilience assessment on coastline changes and urban settlements: a case study in Seribu Islands, Indonesia. Ocean Coastal Management. 54, 391400. DOI: 10.1016/j.ocecoaman.2010.12.003

Gall, S.C., dan Thompson, R.C. (2015). The impact of debris on marine life. Marine Pollution Bulletin. 92, 170-179. DOI: 10.1016/j.marpolbul.2014.12.041

Gregory, M.R. (2009). Environmental implications of plastic debris in marine settings: entanglement, ingestion, smothering, hangers-on, hitch-hiking and alien invasions. Philosophical Transactions of the Royal Society B: Biological Sciences. 364, 2013-2025. DOI: 10.1098/rstb.2008.0265

Jambeck, J.R., Geyer, R., Wilcox, C., Siegler, T.R., Perryman, M., Andrady, A., Narayan, R., dan Law, K. L. (2015). Plastic waste inputs from land into the ocean. Science. 347. DOI: $10.1126 /$ science. 1260352

Maharani, A., Purba, N.P., dan Faizal, I. (2018). Occurrence of beach debris in Tunda Island, Banten, Indonesia. E3S Web of Conferences. 47. DOI: 10.1051/e3sconf/20184704006

Rochman, C.M., Tahir, A., Williams, S.L., Baxa, D.V., Lam, R., Miller, J.T., dkk. (2015). Anthropogenic debris in seafood: plastic debris and fibers from textiles in fish and bivalves sold for human consumption. Scientific Reports. 5. DOI: 10.1038/srep14340

Sur, C. Abbott, J.M., Ambo-Rappe, R., Asriani, N., Hameed, S.O., Jellison, B.M., Lestari, H.A., dkk. (2018). Marine Debris on Small Islands: Insights from an Educational Outreach Program in the Spermonde Archipelago, Indonesia. Frontiers in Marine Science. 5(35). DOI: 10.3389/fmars.2018.00035

Thompson, R.C., Moore, C.J., Saal, F.S.V., dan Swan, S.H. (2009). Plastics, the environment and human health: current consensus and future trends. Philosophical Transactions of the Royal Society B: Biological Sciences. 364, 2153-2166. DOI: 10.1098/rstb.2009.0053. 